\title{
Importance of data acquisition in problem based learning
}

\author{
Valdis Priedols, Armands Grickus \\ Liepaja University, Faculty of Science and Engineering. \\ Address: K. Valdemara iela 4, Liepaja, LV-3401, Latvia
}

\begin{abstract}
This research paper demonstrates untraditional learning and teaching method that is developed from combination of experimentation, usage of computer simulations and problem based learning. Taking all previously mentioned methods together there can be created very successful learning environment which provides students to master electromagnetism more effectively. Research focuses on proper use of data acquisition modules and computer simulations in problem based learning (PBL) teaching method. Based on the results of the research experimental PBL in various cases provides better learning outcomes, but there are also a few occasions where the results aren't so pleasing. Overall PBL provides results that are at least as promising as results of other teaching and learning methods. Therefore this method will be utilized in Liepaja University to teach physics, especially electromagnetism.
\end{abstract}

Keywords: computer simulation, data acquisition, educational technology, electronic learning.

\section{INTRODUCTION}

Learning electricity and magnetism has always been difficult [16]. While studying, students tend to confuse basic concepts, misinterpret schematic representations, do not relate macro and micro relationships in electric circuits, and are unable to link electrostatics and electrodynamics.

The problem with magnetism seems to be even more pronounced due to the fact that humans are not equipped with sensors to gauge magnetism. While electricity can be observed of felt by electric shocks, there is almost no sensual indication of magnetic fields [21]. Unlike mechanical phenomena, which can be sensed visually, electromagnetism is in a realm of physics that is not covered by any one of the five human senses. This is the major reason for difficulties encountered by students of all ages when trying to make electromagnetic concepts concrete [20]. Mostly people that can use their visual imagery can properly master electromagnetism.

Based on research and observations technology instructions in physics should make scientific views more accessible and meaningful [11]. The main goal is that technology should be used in teaching and learning of science as one of learning possibilities and not to have less effective results than other learning styles.

Main reasons for educators to use technology in science are to improve students' physics ability and to improve students' negative reactions toward physics [14].

Most commonly known appropriate reasons when studies are provided by technology are: a) to use computer interfacing equipment to collect and process data of a measurement or experiment; b) to perform experimental or theoretical modelling and to use computer simulations; c) to use research and presentation programs for gathering and displaying information [19].

As an ultimate teaching and learning method problem based learning (PBL) is by far considered as one of the best methods in education [8]. There can be a combination of instructions to solve problems. These instructions consist of specific computer based tasks to be solved through experimentation, paper and pencil exercises and class discussions.

The aim of this research is to consider virtual teaching and learning through the use of experimental PBL and PBL based on computer simulations [23]. This indicates that technology has an important role in virtual teaching and learning.

Hopefully there exist enough positive effects so that combined PBL can be developed in Liepaja University.

\section{MATERIALS AND METHODS}

Common interfacing devices, which are used in the study process, are probes that are plugged into graphing calculators or measuring interfaces that are usually connected to computers. With aid of these devices students are capable of collecting and analyzing data of several measurements.

Data acquisition (DAQ) modules are simply connectable to the universal serial bus (USB) port of personal computer (PC) using standard cable. PC automatically identifies the module and installs the

ISSN 1691-5402 
driver. With aid of USB port data can be transferred more quickly and there can be performed multiple input/output (I/O) operations simultaneously.

Most of the data acquisition modules are compact and portable allowing users to realize measurements out of the lab [3]. There are no overall minuses because the choice of the data acquisition module depends on the needs of every user.

\section{$U S B-D A Q$}

Usually all measurements in physics in Liepaja University are realized with aid of measuring interface Cobra3 - basic unit, provided by PHYWE. A lot of measurements can be taken with this interface, but there exist certain problems, that prevent students from using it. To use the interface in specific experiments a special measuring module has to be used which has to be purchased and does not come in the original packaging. Another considerable fact is that using the original packaging experimentation cannot be done in places where there is no electricity.

Considering all these facts a decision has been made to use a low cost data logger provided by Firmware Factory. It has several necessary options. In normal operation it operates autonomously, collecting data and providing control as required [2]. When plugged into a USB port, DAQ appears on the PC like a removable disk and it can be used as storage. It has a wide range of peripheral I/O. In addition to functioning as a flash drive, DAQ has a data acquisition - process control engine and a real time clock that allow it to function autonomously when not connected to PC.

As evidence shows it is significant that all measurements are taken with appropriate device which is easy to use.

\section{Computer simulations}

Computer simulations are applications of special interest in physics teaching because they can support powerful modeling environments involving physics concepts and processes [4].

A number of applications are available and was considered based on experience and results of other researches, aiming to stimulate students' active engagement and offering the opportunity to work under conditions that are extremely difficult, costly or time consuming to be created in the classroom or even the physics lab. The use of such applications has developed a new research field in physics education, since it radically changed the framework under which physics teaching is being understood and implemented. Computer simulations are considered as a part of teaching physics through PBL [7].

If educators use tools that are virtual then there must be a platform that combines together all the options that are necessary. Local e-learning platform has to be used in teaching and learning process.

\section{RESULTS AND DISCUSSION}

\section{Combined PBL, advantages and disadvantages}

Today's information community expects graduates not only to have a specific knowledge base but also be able to apply this knowledge to solve complex problems in an efficient way. Educational research has shown that successful problem solvers possess an organized and flexible base and master the skills to apply this knowledge for problem solving.

PBL can be recognized from other teaching learning styles with several characteristics such as learning is student centered, learning occurs in small groups under the guidance of a tutor. The tutor is a facilitator or guide. One of the most recognizable characteristic of PBL is that problems are encountered before any study has occurred. Students deal with real life problems, so they acquire skills that will be necessary in real life situations.

PBL can be used to study almost every subject and there is no significant proof that this learning method is more effective than conventional learning. But there are several positive signs: students found PBL to be more nurturing and enjoyable than conventional learning, PBL graduates performed as well as students who had received conventional learning.

Active learning can be also called as PBL because it's learning environment encourage students to engage in solving problems, sharing ideas, giving feedback and teaching each other [24]. Negative side of active learning is that students' attention to what the instructor was saying decreased as the lecture proceeded. But based on evidence integrating active learning strategies as part of the formal learning sessions can advance students learning.

Advantage of using experimental PBL is that students feel responsible for providing answers to the problems provided in the laboratory instructions, and those they encounter themselves. They develop skills to solve these problems, and therefore become more competent. Also laboratory time is used efficiently, with all participants fully engaged in the learning process. Students leave the lab more mature and confident about their skills. They know they can solve other problems when they encounter them in other classes or later in industry. Students develop understanding of how data acquisition system works and develop their own skills to solve hardware and software problems [17]. They also learn data acquisition techniques and software applications to solve real world problems.

Disadvantage is that students may initially struggle with PBL when this approach is new to them. They may not be prepared to answer questions posed by the instructor, they may want the instructor to solve all problems for them. Students may struggle with software and hardware for data acquisition. Learning how to use new software in one lecture can be a 
challenge also laboratory assignment may not be completed during the given time.

\section{Computer simulations in physics teaching}

Learning physics is often considered to be a difficult pursuit. In most cases students can no relate theory with real life, they cannot t name examples that relate to real life problems. A variety of computer applications have been developed and used in teaching physics to improve learning process [12].

Among the various applications, computer simulations have achieved special importance in physics teaching and learning. Simulations offer new educational environment which aim to enhance teachers' instructional potentialities. Computer simulations offer a great variety of opportunities for modelling concepts and processes.

They are open learning environments that provide students with the opportunity to develop their understanding about phenomena and physical laws through a process of making hypothesis and testing ideas, isolate and manipulate parameters and therefore helping them to develop an understanding of the relationship between physical concepts and variables, investigate phenomena which are difficult to experience in a classroom or lab setting because it is extremely complex, technically difficult or dangerous, money consuming or time consuming, or happen too fast [13].

There are commonly known two types of computer models in physics. The first one is exploratory models, which are constructed by experts to represent domain knowledge. Usually they are micro - worlds that simulate physical processes and laws. Such micro worlds encourage students explore and interact with them, handle parameters and observe their results.

The second is expressive models, which allow students express their own ideas on a domain. They provide learners with tools to define relationships between concepts, explore the consequences of relationships that students have defined and learn through an active process of representing their own models.

Computer simulations are used to enhance traditional instruction. Computer simulations are used as supplement or alternative to traditional teaching [5].

There are few results that students who used computer simulations in their study were able to get higher scores in tests, but those results don't prove that the knowledge they learned is consistent [6].

Simulations can also be used as a remedy to prepare for laboratory activities. This method shows results of increasing interest in specific courses and overall improvement of academic performance.

There is a danger that with computer simulation, students will see no need to take responsibility for their own understanding, to verify, or to challenge. This can result in students learning science passively.
Studies on how computer simulation improves learning performance have produced diverse results, with some of them finding that simulation based learning does not significantly improve the test results of learners.

\section{High performance data acquisition on USB}

The opinion for plugging data acquisition module into PCI bus to get higher performance is no longer so commonly seen. The reason for that is the usage of USB ports that perform as fast as PCI based cards.

Utilizing the USB as a data portal provides many advantages for data acquisition (DAQ)[1]. For example the software installation is much simpler, because users do not have to open their PC and configure the hardware. System software will automatically form a logical connection from DAQ channel to a destination within the application software and hardware setup [22]. Applications simply need to identify the logical pipe they wish to connect with and the system software ensures that data travels to the right destination. Application software does no need to know the details of peripheral addressing, interrupt placement, or other installation dependent parameters as it must for PCI plug-in cards.

The USB also has electronic advantages. The bus can power the peripheral so that the DAQ system does not need its own power source. This kind of specification is very useful if it is necessary to do measurements in different kinds of environment.

\section{Moodle}

Most common e-learning platform also known as virtual learning environment that is used in teaching process is Moodle [15]. Virtual learning environment provides different learning materials such as videos, music files, images, links to other web sites, animations, simulations. There are also tools provided by Moodle to test the level of knowledge. Moodle provides online space for discussion through the form of chats and forums.

Based on evidence Moodle can be used to support learning but not to replace learning process [15]. The structure and quality of materials that are put in Moodle must be strongly considered otherwise the learning process could be meaningful. Hardest part of good learning materials is to create learning materials that develop ability to solve problems that represent different situation or problems because students have difficulties with applying laws and equations to real life problems.

In several regions Moodle is most commonly used by teachers and professors [15].

\section{CONCLUSION}

Science and technology develop through the exchange of information, much of which is presented as moving images, diagrams, illustrations and models that summarize information and help understand 
scientific data and phenomena. To fully understand the nature of scientific phenomena, students should be exposed to different types of models, such as verbal, mathematical and visual models.

Different teaching strategies can be used to provide suitable education support to enhance the effectiveness of learning. Technologies are often used by teachers to improve teaching and learning process.

Instructional computer simulations and other applications of the computer in the classroom will appropriately continue to be an important part of teaching physics.

The laboratory experiments that students carry out as part of the course are of exploratory nature and are often accompanied by real time data collection. Most of these experiments cannot be done with usual methods because most of them require a very long time of observation or in opposite the process that must be measured is very fast. Experiments are supplemented with $2 \mathrm{D}$ and $3 \mathrm{D}$ visualizations and simulations [18]. The visualizations allow students to make abstract ideas concrete. Most of physics concepts can be modeled with mathematical relationships [10]. Computer generated models of these relationships are provided for learners in every field of physics [9].

Based on research it is possible to develop virtual teaching and learning in Liepaja University. Computer simulations are already used in learning process in course of electromagnetism. There does not exist absolute arguments that simulations and PBL cannot be used in teaching and learning process. So these methods will be more deeply considered and properly used in the field of physics along with all the necessary experimentation and usage of computer simulations.

\section{REFERENCES}

[1] S. Thanee, S. Somkuarnpanit and K. Saetang, Eds., FPGA Based Multi Protocol Data Acquisition System with High Speed USB Interface: International Multi Conference of Engineers and Computer Scientists 2010 Vol II, March 17-19, 2010, Hong Kong, China.

[2] Biswajit Ray, Eds., An Instrumentation and Data Acquisition Course for Electronics Engineering Technology Students: 2003 American Society for Engineering Education Annual Conference \& Exposition, 2003, Bloomsburg, USA.

[3] R. J. Robinson and J. Welli, Eds., Introducing Data Acquisition and Experimental Techniques to Mechanical Engineering Students in the Freshmen Year: 2002 American Society for Engineering Education Annual Conference \& Exposition, 2002, Rochester, USA.

[4] A. Jimoyiannis and V. Komis, "Computer simulations in physics teaching and learning: a case study on students understanding of trajectory motion," Computers \& Education, vol. 36, pp. 183-204, Nov. 2000.

[5] N. Rutten, W. R. van Joolingen and J. T. van der Veen, "The learning effects of computer simulations in science education,” Computers \& Education, vol. 58, pp. 136-153, Jul. 2011.
[6] L. P. Rieber, S. Tzeng and K. Tribble, "Discovery learning, representation, and explanation within a computer-based simulation: finding the right mix," Learning and Instruction, vol. 14, pp. 307-323, 2004.

[7] K. Chang, Y. Chen, H. Lin and Y. Sung, "Effects of learning support in simulation-based physics learning," Computers \& Education, vol. 51, pp. 1486-1498, Jan. 2008.

[8] F. Dochy, M. Segers, P. van den Bossche and D. Gijbels, "Effects of problem-based learning: a metaanalysis," Learning and Instruction, vol. 13, pp. 533-568, 2003.

[9] W. Christian and F. Esquembre, "Modeling Physics with Easy Java Simulations,” The Physics Teacher, vol. 45, pp. 475-480, Nov. 2007.

[10] K. Perkins, W. Adams, M. Dubson, N. Finkelstein, S. Reid and C. Wieman, "PhET: Interactive Simulations for Teaching and Learning Physics,” The Physics Teacher, vol. 44, pp. 1823, Jan. 2006.

[11] N. Finkelstein, W. Adams, C. Keller, K. Perkins and C. Wieman, "High-Tech Tools for Teaching Physics: the Physics Education Technology Project,” Journal of Online Learning and Teaching, Sep. 2006.

[12] C. E. Wiemann, W. K. Adams and K. K. Perkins, "PhET: Simulations That Enhance Learning," Science, vol. 322, pp. 682-683, Oct. 2008.

[13] T. D. Jong and W. V. Joolingen, "Scientific discovery learning with computer simulations of conceptual domains," SAGE Publications, vol. 68, pp. 179-202, Nov. 2007.

[14] J. Bryan, “Technology for Physics Instruction,” Contemporary Issues in Technology and Teacher Education, vol. 6(2), pp. 230-245, 2006.

[15] T. Martin-Blas and A. Serrano-Fernandez, "The role of new technologies in the learning process: Moodle as a teaching tool in physics,” Computers \& Education, vol. 52, pp. 35-44, Jun. 2008.

[16] Y. J. Dori and J. Belcher, "How does technology-Enabled Active Learning Affect Undergraduate Students Understanding of Electromagnetism Concepts," The Journal of the Learning Sciences, vol. 14(2), pp. 243-279, 2005.

[17] C. Wiemann and K. Perkins, "Transforming Physics Education,” Physics Today, vol. 58(11), pp. 36-50, Nov. 2005.

[18] N. D. Finkelstein, W. K. Adams, C. J. Keller, P. B. Kohl, K. K. Perkins, N. S. Podolefsky and S. Reid, "When learning about the real world is better done virtually: A study of substituting computer simulations for laboratory equipment," The American Physical Society, vol. 1, pp. 1-8, Oct. 2005.

[19] R. N. Steinberg, "Computers in teaching science: To simulate or not to Simulate,” Phys. Ed. Res, vol. 68, pp. S37-S41, 2000.

[20] M. E. Gredler, "Games and simulations and their relationships to Learning," Handbook of Research on Educational Communications and Technology, pp. 571-581, 2004.

[21] "Improving students understanding of electricity and magnetism,” March 20, 2012. [Online]. Available: http://dscholarship.pitt.edu/11767/1/Jing_Li's_Doctoral_Thesis_4_a\% 26s_format_revised7.pdf. [Accessed: Jan. 30, 2015].

[22] "Benefits \& Potential Dangers of Using USB for Test \& Measurement Applications," [Online]. Available: http://www.controldesign.com/assets/12WPpdf/121024-datatranslation-benefits-dangers-using-usb.pdf. [Accessed: Jan. 30, 2015].

[23] "Problem based learning of Data Acquisition and ComputerBased control Applications in MET Courses," [Online]. Available: https://www.ni.com/pdf/academic/us/journals/ lv02_52.pdf. [Accessed: Jan. 30, 2015].

[24] Y. J. Dori and J. Belcher, "Learning Electromagnetism with Visualizations and Active learning," in Visualizations in Science Education, vol. 1, Models and Modeling in Science Education, J. K. Gilbert, Ed. Springer Netherlands, 2005, pp. 187-216. 